\title{
Teoría y metodología de investigación sobre libros de texto: análisis didáctico de las actividades, las imágenes y los recursos digitales en la enseñanza de las Ciencias Sociales*
}

\author{
Juan Carlos Bel Martínez (1) \\ Juan Carlos Colomer Rubio (D
}

\section{RESUMEN}

Los materiales curriculares en cualquier formato, especialmente el manual escolar de Ciencias Sociales - Geografía e Historia - se ha constituido históricamente como un recurso central en las aulas para esta disciplina. En este estudio planteamos su evolución teórica como problema de investigación en Ciencias Sociales (en el contexto español) en lo que respecta a su contenido, utilización y difusión para plantear una metodología de análisis de manuales basada en el estudio de las actividades y de las imágenes vinculadas a la complejidad cognitiva demandada en ellas. Las conclusiones insisten en el papel del libro de texto como un componente central de la cultura escolar en España e Iberoamérica que requiere de una metodología concreta de investigación para su necesaria transformación en un elemento útil para la enseñanza.

\section{PALABRAS CLAVE}

libros de texto; enseñanza de la Historia; enseñanza de la Geografía; didáctica; metodología.

\footnotetext{
*Este trabajo forma parte del Proyecto "Competencias sociales para una ciudadanía democrática: análisis, desarrollo y evaluación” (EDU2015-65621-C3-1-R), del Plan Nacional de I+D+i del Ministerio de Economía, Industria y Competitividad (MINECO) del Gobierno de España, cofinanciado con fondos FEDER de la Unión Europea. 'Universitat de València, Valencia, España.
} 


\title{
RESEARCH THEORY AND METHODOLOGY ON TEXTBOOKS: DIDACTIC ANALYSIS OF ACTIVITIES, PICTURES AND DIGITAL RESOURCES IN SOCIAL SCIENCES EDUCATION
}

\begin{abstract}
Didactic materials in any format, especially Social Sciences textbooks Geography and History -, have been historically constituted as a central resource in the classroom for this discipline. In this study we propose its theoretical evolution as a research problem in Social Sciences (in the Spanish context) in terms of content, use and diffusion, to propose a methodology of textbooks analysis based on the study of activities and pictures linked to the cognitive complexity demanded in them. The conclusions insist on the role of textbooks as a central component of school culture in Spain and Ibero-America that requires a specific research methodology for its necessary transformation into a useful element for teaching.

KEYWORDS

textbooks; History teaching; Geography teaching; didactics; methodology.
\end{abstract}

\section{TEORIA E METODOLOGIA DE PESQUISA DE LIVROS DIDÁTICOS: ANÁLISE DIDÁTICA DE ATIVIDADES, IMAGENS E RECURSOS DIGITAIS NO ENSINO DE CIÊNCIAS SOCIAIS}

\author{
RESUMO
}

Os materiais curriculares em qualquer formato, especialmente o manual didático de Ciências Sociais - Geografia e História —, têm sido historicamente considerados um recurso central nas práticas de sala de aula desta disciplina. Dessa forma, nesse trabalho propomos a análise da sua evolução teórica como um problema que compõe o âmbito das pesquisas em Ciências Sociais (no contexto espanhol) no que diz respeito ao seu conteúdo, uso e disseminação, com o objetivo de construir uma metodologia de análise dos manuais baseada no estudo das atividades e das imagens existentes, associadas à complexidade cognitiva demandas por elas. As conclusões insistem na importância do livro-texto como um componente central na cultura escolar espanhola e iberoamericana, o que requer uma metodologia concreta de investigação para a sua transformação em um elemento útil para o ensino.

\section{PALAVRAS-CHAVES}

livros didáticos; ensino de História; ensino de Geografia; didática; metodologia. 


\section{INTRODUCCIÓN: A 20 AÑOS DE “EL LIBRO DE TEXTO IDEAL”}

Hace pocos meses se cumplían 20 años de la publicación en castellano del artículo del historiador y filósofo alemán Jörn Rüsen, "E1 libro de texto ideal" (Rüsen, 1997), una de las primeras traducciones en español del teórico europeo que tuvo una clara influencia en los trabajos sobre manuales escolares. En dicho estudio, el autor se centraba en considerar diversos criterios de análisis de libros de texto de Historia enfocados a determinar el modo en que estos podían contribuir al desarrollo de la conciencia histórica. De hecho, uno de los primeros déficits que encontraba era la falta de una obra que aunara criterios de análisis de estos materiales, estudios sobre su utilidad práctica y trabajos empíricos que contribuyeran a una mejor elaboración de los mismos. El reto enunciado por Rüsen fue recogido posteriormente en estudios como los de Valls $(2007,2008)$ o el de Prats (2012) en el contexto español, aportando sugerencias relevantes que han constituido la base metodológica sobre la cual han evolucionado los estudios sobre manuales en Didáctica de las Ciencias Sociales. ${ }^{1}$

Hoy podemos afirmar que la manualística — definida por Escolano (2013) como el campo de conocimiento que estudia los libros de texto mediante diferentes perspectivas y enfoques, desde su composición interna, pasando por sus formas de producción y uso - se ha convertido en una línea de trabajo de gran relevancia en el seno de la investigación educativa iberoamericana y europea (Mahamud y Badanelli, 2016; Rodríguez-Rodríguez et al., 2016; Valls, 2007). Por consiguiente, el déficit que denunciaba Rüsen se ha visto notablemente reducido en este período, con un gran número de investigaciones que han abordado el análisis de los manuales escolares de forma amplia. Como consecuencia de esto se ha dado cierta dispersión metodológica que, pese a no ser un aspecto negativo, sí ha supuesto en muchos casos una contribución débil a este campo de conocimiento por resultar insuficiente la explicación detallada de los métodos de investigación empleados o su escasa renovación (Mahamud y Badanelli, 2013). Junto con ello, los estudios se han centrado especialmente en los materiales en papel, lo que ha dificultado un análisis en profundidad de otros soportes, como el digital en su contexto de progresiva introducción en las escuelas.

Con el presente trabajo pretendemos realizar un examen sobre lo que ha supuesto la evolución teórica y metodológica de los trabajos sobre manualística en Didáctica de las Ciencias Sociales desde la publicación del trabajo de Rüsen en 1997 destacando las principales aportaciones llevadas a cabo, especialmente en el

1 Entendemos la Didáctica de las Ciencias Sociales como el área de conocimiento que examina las formas y modos de aprendizaje de las materias que tradicionalmente estudian al ser humano en el tiempo, en el espacio y en relación con la sociedad. Para el contexto español, las “Ciencias Sociales” ha resultado ser la denominación tradicional que desde los años 70 se lleva dando a las materias escolares que engloban principalmente las enseñanzas de Geografía e Historia, sobre todo en Educación Secundaria. Para el caso de Brasil, las materias de "Historia" y de "Geografía" se ha mantenido como disciplinas separadas tanto en las etapas en Enseñanza Fundamental - Educación Primaria - como en Secundaria con esa misma denominación. 
contexto español, y difundidas en importantes publicaciones periódicas, así como en el dossier on-line del Proyecto MANES. Junto con ello, mostraremos una propuesta metodológica de análisis didáctico para los materiales en soporte en papel $\mathrm{y}$ en digital.

Es indudable que, pese a los años transcurridos desde la publicación de "El libro de texto ideal", el manual continúa presentando un papel omnisciente en la práctica escolar (Martínez y Alarcón, 2016), algo que no se verá modificado con la introducción de nuevos soportes digitales (Rodríguez-Rodríguez et al., 2016). Es por ello por lo que necesitamos de nuevas estructuras y propuestas metodológicas que ayuden a comprender el libro de texto como un producto cultural cuyo análisis permita la introducción de novedades en la formación del alumnado.

\section{LOS MANUALES COMO PROBLEMA DE INVESTIGACIÓN EDUCATIVA}

El libro de texto o manual - entendido este como "el recurso material específico de trabajo de enseñanza en las situaciones de aula en los ámbitos institucionales de escolarización (...) que suele responder a una disciplina concreta de las prescritas por el currículum oficial" (Martínez-Bonafé, 2008, p. 62) - resulta fundamental como producto de la cultura empírica de la escuela. De hecho, desde la implantación del sistema educativo tecnocrático de masas en el siglo XX, la importancia de este material didáctico no ha hecho más que aumentar en contextos como el europeo e iberoamericano, lo que a su vez ha llevado a una mayor preocupación por su estudio desde las esferas académicas y al establecimiento de la manualística como disciplina investigativa que analiza los libros de texto como fuente historiográfica y género textual, además de examinar diferentes dimensiones pragmáticas derivadas de este material escolar (Escolano, 1998, 2013). En este sentido, la fundación en 1975 del Georg Eckert Institute en Alemania y la creación en 1980 del Proyecto Enmanuelle en Francia inspiraron - especialmente el segundo - la constitución del Proyecto MANES en 1992 en España, centrado en la catalogación y estudio de los manuales españoles y latinoamericanos de los siglos XIX y XX (Teive, 2015; Tiana, 2000). Además, también destaca el Centro Internacional de la Cultura Escolar (CEINCE) creado en 2006 que, en colaboración con el mencionado Proyecto MANES, se ha constituido como un referente en el análisis de manuales y en su conservación como patrimonio histórico-educativo (Escolano, 2013). Junto con estos centros de investigación han surgido iniciativas como la IARTEM (International Association for Research on Textbooks and Educational Media) que demuestran la importancia de estos ámbitos de estudio, como se ha constatado recientemente en el congreso IARTEM en Colombia (Gómez-Mendoza et al., 2016).

La creación de estos organismos de investigación se produjo tras siglos en los que el manual se afianzó como un instrumento clave en la expansión de los sistemas nacionales de educación. En la actualidad, la inclusión de la tecnología digital en los libros de texto está abriendo la puerta a una nueva generación de materiales curriculares, a pesar de que su implantación en las aulas no sea generalizada (Peirats et al., 2016). Estos recursos mantienen, en muchos casos, la misma fisionomía y formato que los libros de texto en papel y queda por ver si estamos ante un producto 
renovador que cambie las dinámicas de aula. En cualquier caso, la complejidad que caracteriza a estos materiales curriculares - tanto en papel o en digital - como facilitadores del aprendizaje de los alumnos/as, hace que su diseño, composición y utilización se vea alterado por toda clase de condicionantes políticos, técnicos y pedagógicos que afectan a sus contenidos y a su forma de tratarlos.

De hecho, el factor que más relevancia ha ido ganando en el diseño y contenido didáctico de los manuales (en este caso españoles) han sido las preferencias del mercado al que van dirigidos. Los libros de texto - como productos comerciales que compiten con el resto de la oferta editorial (Badanelli et al., 2009) - deben adaptarse a las demandas del mercado, las cuales están guiadas especialmente por las preferencias del profesorado que es quien en última instancia decide qué manuales se comprarán. De esta forma, la existencia de una parte importante del colectivo docente que hoy en día se inclina por utilizar materiales ya elaborados y con los conocimientos preparados para ser trasladados al alumnado, ha llevado - entre otros factores - a que la gran mayoría de recursos didácticos hayan sido editados en este sentido.

A diferencia del caso español, en otros contextos el papel del Estado es más importante a la hora de entender la composición y distribución del libro de texto. Así, contamos con situaciones como la de Brasil donde los organismos públicos supervisan el contenido de los manuales y optan por un libro en concreto que es difundido entre las escuelas. En otro orden, Chile ha optado por la edición de textos escolares públicos gratuitos que son distribuidos ampliamente. Todos estos modelos reducen a la mínima expresión el papel del docente en la composición de contenidos dentro de su contexto (Rodríguez-Rodríguez y Martínez-Bonafé, 2016) y comparten con el sistema español la distribución de materiales prediseñados.

En el caso de la Didáctica de las Ciencias Sociales, si tomamos el ejemplo concreto de los manuales de Historia, como también sucede en Geografía, otra de las variables que sigue persistiendo y que marca los materiales de esta disciplina son las tradiciones y rutinas escolares asociadas a ella dentro de la cultura escolar (Schmidt, 2012). El concepto de Código disciplinar, entendido este como "una tradición social configurada históricamente y compuesta de un conjunto de ideas, valores, suposiciones y rutinas, que legitiman la función educativa atribuida a la Historia y que regulan el orden de la práctica de su enseñanza" refuerza esta idea (Cuesta, 1997, p. 20).

Pese al influjo de estas tradiciones y rutinas, al observar y analizar los diversos elementos (texto, imágenes, etc.) que contienen los primeros ejemplares de manuales escolares es posible comprobar el modo en que han variado en su conjunto. De este modo, una dinámica común en muchos de los libros del siglo XIX era la de presentar gran parte del texto expositivo por medio de "la forma catequística de preguntas y respuestas" (Valls, 2007, p. 76), algo que facilitaba la memorización de los contenidos. Además, cuando se incorporaba alguna imagen entre las páginas estas tenían una clara función decorativa - algo que parcialmente continúa en la actualidad - y su presencia fue escasa hasta finales del siglo XIX cuando los avances en técnicas de impresión hicieron que los manuales incluyeran una cantidad progresiva de imágenes (Cuesta, 1997). 
A lo largo del siglo XX se introdujeron muchos otros cambios condicionados por el contexto político, social, económico y tecnológico de cada momento. Todo ello derivó en la transmisión de distintos discursos en los manuales, pero también influyó en las propuestas didácticas que, pese a seguir centrándose en la memorización de contenidos factuales, evolucionaron a partir de la década de 1970 con algunas innovaciones provenientes de nuevas corrientes pedagógicas (Escolano, 1998). Atendiendo a su contenido y diseño, estos manuales continuaron presentando un marcado carácter tradicional (con contenidos culturalistas y omnicomprensivos, aunque cada vez con un sentido menos nacionalizador), el cual perdura hoy en día pese a las evidentes variaciones externas (imágenes, actividades...) (López-Facal, 2010). Todo ello nos lleva a determinar que el trayecto trazado por los materiales escolares españoles de Historia, pero también de otras disciplinas académicas, "es una mezcla de innovaciones modernizadoras y de persistencias arcaizantes"(Valls, 2007, p. 102).

Esto puede buscarse, como ya ocurría en épocas pasadas (Escolano, 2006; Rodríguez-Rodríguez y Martínez-Bonafé, 2016), en unos códigos de producción de los libros de texto que han respondido y remiten al modelo de la educación tradicional e imperante en cada época histórica. Los contenidos que el autor seleccionaba venían determinados según los criterios fijados por los usos convencionales difundidos en la escuela, ya fueran los establecidos por la tradición erudita (en el caso de textos sobre disciplinas) o por el ethos y la mentalidad social dominante (en los libros de lectura), o por la propia metodología de enseñanza (Escolano, 2013). Los intereses del sujeto lector eran ignorados y sustituidos por una especie de "lector modelo" o tipo ideal y trascendental que, en todo caso, respondía al estereotipo del sujeto pasivo que leía, memorizaba, recitaba o copiaba por escrito los textos propuestos de manera uniforme (Mahamud y Badanelli, 2016). Así, en la estructura de los manuales más difundidos el texto del libro ocupa la parte central de las páginas y las actividades que remiten normalmente al mismo texto (Sáiz y Colomer, 2014) o los recursos icónicos o gráficos son siempre accesorios y a libre disposición de la programación de aula.

En este contexto, el peso de determinadas leyes educativas como la española han ido coartando la autonomía del profesorado hacia un currículo que pone el acento en los contenidos factuales y en estándares de evaluación homogéneos para cada edad escolar (Parra et al., 2015). Ello se ha trasladado en una mayor dependencia del manual y la limitación de la innovación en la creación de materiales alternativos que doten de más peso a las fuentes, como documentos históricos escritos o imágenes para el trabajo de otros contenidos. Ejemplos de estos nuevos materiales los encontramos, para el caso español, en la labor de los grupos de innovación educativa a mediados de los ochenta y noventa del siglo XX como Kairós, Gea-Clio o 13-16. La introducción de la tecnología digital a partir de la década del 2000, que podría verse como una posible modificación de las estructuras tradicionales del manual escolar, en muchas ocasiones, lo único que ha supuesto ha sido la perpetuación de códigos y herramientas ya muy utilizadas y nada alternativas.

Como hemos comprobado, la incidencia que el libro de texto ha tenido y tiene dentro de la propia cultura escolar lo convierte en un elemento clave en áreas como la Didáctica de las Ciencias Sociales en España o de Geografía e Historia 
en Brasil. Así, se han desarrollado unas líneas de trabajo relevantes que ponen el acento en el manual como problema de investigación por su contenido, difusión o utilización didáctica.

\section{ESTADO ACTUAL DE LA INVESTIGACIÓN SOBRE LOS MANUALES ESCOLARES EN DIDÁCTICA DE LAS CIENCIAS SOCIALES}

La importancia que han adquirido los manuales para el campo de la investigación educativa se ha debido, en gran medida, a que se tratan de unas fuentes documentales privilegiadas que permiten aproximarse a aquello que acontece en las aulas, ya sea adoptando el prisma de cualquiera de las didácticas específicas, el de la Historia de la Educación o de cualquier otro campo de investigación concreto como la manualística (Escolano, 1998; Mahamud, 2014; Ossenbach, 2010; Tiana, 2000; Valls, 2007). El cuantioso volumen de estudios realizados sobre los manuales escolares ha llevado a que sea necesaria cierta catalogación u organización de estas investigaciones. Para ello se pueden establecer multitud de criterios, dependiendo del nivel educativo al que van dirigidos los libros, la materia que desarrollan, así como otros elementos que delimitan al manual como objeto de estudio (Bufrem et al., 2006; Mahamud, 2014; Teive, 2015). En nuestro caso consideramos que es preferible esbozar un modesto "estado de la cuestión" de estos últimos 20 años - desde la publicación del trabajo de Rüsen (1997) — atendiendo a la materia propia del libro, para plantear la propuesta metodológica de análisis que aportamos. Con este fin, clasificaremos estas investigaciones en función de diferentes facetas de los manuales analizadas desde la investigación educativa (Badanelli et al., 2009). Para ello focalizaremos nuestra atención, por cuestiones de espacio, al territorio español, sin olvidar las transferencias culturales con el contexto europeo e iberoamericano. A modo de balance previo de esta recopilación, queremos destacar que la gran mayoría de estudios realizados en los últimos 20 años se corresponden a análisis de los manuales de Educación Secundaria y Bachillerato, especialmente de los libros de Historia. Por su parte, contamos con escasos trabajos sobre la materia de Geografía, aunque destacan las investigaciones realizadas por el equipo de Horacio Capel en la década de los ochenta (Capel, 1983; Capel et al., 1988).

Si tomamos la investigación de Fernández (2005), aquí ya se planteaba una revisión de casi 600 investigaciones sobre manuales y se describían cuatro grandes campos de estudio en manualística: en primer lugar, estudios críticos, históricos e ideológicos sobre los contenidos; en segundo lugar, aquellos que abordan los estudios formales, lingüísticos y psicopedagógicos referidos, entre otras cosas, a la adecuación didáctica general y/o específica; por otro lado, los trabajos sobre las políticas culturales, editoriales y económicas; y finalmente, los estudios centrados en el papel de los manuales en el diseño y desarrollo de la cultura escolar. El gran número y diversidad de investigaciones existentes hace que muchos trabajos se puedan adscribir a más de una línea de investigación al mismo tiempo. El método seguido para conformar el siguiente estado de la cuestión ha partido de un vaciado bibliográfico del dossier on-line del Proyecto MANES sobre investigaciones de 
manuales de Geografía e Historia publicadas en el período 1997-2017. Dicha compilación se ha completado con una serie de publicaciones en revistas científicas de amplia difusión sobre investigación educativa, así como de Didáctica de las Ciencias Sociales. No obstante, el gran volumen de estudios localizados ha llevado a priorizar aquellos más relevantes por su incidencia en la evolución de la investigación sobre manualística, concretamente de Geografía e Historia o Ciencias Sociales en el contexto español con influencias en otras zonas de Iberoamérica.

\section{ESTUDIOS CRÍTICOS, HISTÓRICOS E IDEOLÓGICOS SOBRE LOS CONTENIDOS DE LOS MANUALES}

El primero de estos campos de investigación (estudios críticos, históricos e ideológicos sobre los contenidos) se ha convertido en el terreno en que se han concentrado la mayoría de estudios sobre manuales de Ciencias Sociales, Geografía e Historia y, a su vez, al que se han hecho las aportaciones más relevantes. Estos trabajos indagan en la gran diversidad de sesgos y condicionantes que muestran los contenidos de los libros de texto en un momento histórico concreto o a lo largo de cierta época. Por la perspectiva adoptada, muchos de estos estudios no se han realizado tanto desde la Didáctica de la Geografía o la Historia sino desde la Historia de la Educación, al abordar el tratamiento y orientación de ciertos contenidos específicos en los manuales escolares de diferentes momentos del pasado. Algunas razones de este fenómeno pueden buscarse en que la mayoría de autores disponen de una formación metodológica disciplinar y, por lo tanto, las técnicas de investigación que emplean son las propias del campo de las Humanidades. Junto con ello, la deconstrucción del manual escolar ha empezado por acometer un análisis del contenido de su elemento nuclear: el textual, lo que ha preocupado a investigadores y especialistas en la materia frente a otros aspectos considerados secundarios como los recursos contenidos en ellos (Fernández, 2005).

En este sentido, el análisis de la incidencia de unas u otras ideologías, perspectivas historiográficas y finalidades socioeducativas vinculadas a la enseñanza de la Historia han sido objeto de estudio por este tipo de trabajos, dando lugar a que muchos de ellos - como el de García-Puchol (1993) o los de Valls (2007, 2008) - hayan ayudado a reconstruir la denominada historiografía de la historia escolar. Este es un factor diferencial de los estudios sobre los manuales de Historia con respecto a los de otras disciplinas. En otras ramas de conocimiento el lugar ocupado por el análisis del enfoque historiográfico utilizado en los manuales escolares ha sido dedicado a investigaciones centradas en el currículo oculto, entendido este como la transmisión de intenciones y valores no explícitos en los contenidos educativos formales (Badanelli et al., 2009).

Como ya adelantábamos anteriormente, existen numerosos estudios en el caso español que han abordado el análisis de los contenidos en los libros de texto del pasado. Así, muchos de ellos han investigado contenidos geográficos e históricos concretos del Bachillerato decimonónico (Benso y Rivas, 2002), de la educación franquista (Castillejo, 2003,2008) o de materiales editados durante varios de estos períodos, como el trabajo de Benedito et al. (2012) sobre los manuales de Geografía 
de la segunda mitad del siglo XX o el de Pozo-Nogales (2014) sobre la enseñanza de la Historia hasta el final de la dictadura. Por otro lado, diversas investigaciones han indagado en el uso de la imagen en los libros de texto del franquismo, o en los de todo el siglo XX (Valls, 2007), y en su contribución a la formación de la identidad nacional (Campos, 2010). La construcción de esta identidad por medio de los materiales franquistas ha sido analizada detalladamente por Boyd (2000), así como las ideas proferidas por dichos manuales sobre el africanismo y las culturas islámicas (Parra, 2016).

Por otro lado, la formación identitaria ha sido un aspecto también trabajado. De este modo, en las dos últimas décadas han proliferado los estudios sobre identidades nacionales - sobre todo la española - (López-Facal, 2010; Rodríguez y Simón, 2014; Sáiz, 2012) aunque también la relación con la territorialidad (Císcar et al., 2012), así como trabajos sobre las identidades europeas y occidentales (Prats, 2001). También se ha abierto un espacio para el análisis y tratamiento de la interculturalidad (Atienza y Van Dijk, 2010) o de la identidad de género contenida en estos materiales (Blanco, 2000; Rausell, 2015; del Castillo, 2015; Bel, 2016).

Si examinamos la evolución analítica que han seguido estos trabajos, Sáiz y Colomer (2014) afirman que se ha pasado de estudios centrados en el tratamiento de contenidos concretos dentro de los manuales al trabajo sobre la orientación historiográfica de conceptos presentes en los mismos (como el androcentrismo, etnocentrismo, etc.). Pese a que la contribución de todas estas investigaciones es esencial ya que permiten revisar críticamente la selección social, cultural e histórica de los contenidos desarrollados en los libros, su radio de acción termina ahí porque no debemos ignorar las resistencias y/o lecturas que profesorado y alumnado pueden realizar en su contexto educativo (Fernández, 2005).

\section{INVESTIGACIONES SOBRE LA ADECUACIÓN}

\section{DIDÁCTICA DE LOS MANUALES ESCOLARES}

Por otro lado, otro gran grupo de los mencionados es en el que se adscriben las numerosas investigaciones que forman los estudios formales, lingüísticos y psicopedagógicos referidos, entre otras cosas, a la adecuación didáctica general y/o especifica. Además, es en esta línea en la que se enmarca la propuesta metodológica que presentaremos a continuación.

Las investigaciones que forman este conjunto comparten un mismo objetivo: mejorar en el sentido didáctico las propuestas de los manuales, generalmente, tomando como referencia las capacidades que se supone que poseen los alumnos de la edad a la que van dirigidos. Para ello, se centran en analizar el lenguaje utilizado en los libros de texto, su estructura interna como medio para facilitar el aprendizaje, las actividades a realizar por parte del alumnado o el uso de diferentes recursos (TICs, imágenes o materiales audiovisuales), entre otros.

Respecto a esta clase de investigaciones, debemos destacar el estudio introductorio de Valls (2007) en el que analizaba el tratamiento didáctico que habían recibido las imágenes en los manuales de Historia y evidenciaba el modo en que estos recursos habían pasado de aparecer como meras ilustraciones a ser tratados 
(aunque no del todo) como documentos históricos. Esta línea de investigación fue seguida por los trabajos de Sáiz $(2011,2012,2015)$, que inició una comprobación sistemática de la incorporación de las Competencias Básicas en los manuales de Historia del sistema educativo español, la cual se centraba inicialmente en estudiar si las actividades contenidas en ellos habían incorporado un tratamiento complejo de las competencias históricas. Todo ello evolucionó en estudios posteriores enfocados a indagar el grado en que estas actividades estaban favoreciendo o no el desarrollo del pensamiento histórico. No obstante, una contribución relevante de estos trabajos han sido las aportaciones académicas que les han seguido y que se han apoyado en su modelo metodológico para alcanzar distintos objetivos de investigación (Gómez, 2014; Sáiz y Colomer, 2014; Bel, 2017).

Sin embargo, otros estudios han analizado elementos concretos de la adecuación didáctica de los manuales de Ciencias Sociales, Geografía e Historia y lo han hecho sin servirse de este método de investigación. Así, Gómez et al. (2012) exploran el tratamiento que recibe la Historia del Arte en libros de CCSS, Gómez y López (2014) han diseñado y aplicado un instrumento de análisis sobre el uso que se da a las imágenes, Rodríguez y Simón (2014) inciden en la función de las actividades para formar la identidad nacional y Sáez-Rosenkranz (2016) examina en su tesis las actividades de los libros de texto, en este caso trascendiendo del ámbito español al ámbito chileno.

Con respecto a los libros de texto de Geografía, esta es una línea de investigación que presenta diversos trabajos en este ámbito. De este modo, en un informe de la Asociación de Geógrafos Españoles (2000) se evalúan las propuestas didácticas de los libros y se plantean líneas de mejora, y de Miguel (2013) estudia la insuficiente incorporación de sistemas digitales de geoinformación en estos manuales. Esta última línea se vincula claramente a la deconstrucción que ha sufrido el manual digital, que ha pasado de ser un material cerrado en papel a plantear una batería de recursos posibles y dispares para el aula. Algunos autores, por tanto, han estudiado y trabajado este conjunto de herramientas digitales - como las WebQuest - y han analizado su posible aprovechamiento didáctico, aunque aún de forma escasa (Buzo, 2011; Martín, 2004).

\section{ANÁLISIS SOBRE LAS POLÍTICAS DE PRODUCCIÓN EN TORNO AL LIBRO DE TEXTO}

En cuanto al grupo de investigaciones que Fernández (2005) denomina como estudios sobre las políticas culturales, editoriales y económicas, estas analizan los procesos de diseño y producción de los manuales escolares, así como su distribución y consumo en las aulas. Este es un campo esencial para aproximarnos a la aceptación de unos u otros materiales en las escuelas y sin embargo contamos con escasos estudios dentro de las fechas analizadas.

No obstante, existen algunos ejemplos a destacar que han incidido en esta línea. Entre ellos, los trabajos de Cuesta (1997) y Valls (2007) han analizado la producción de manuales escolares de Historia durante los siglos XIX y XX (la mayoría de los empleados en esta etapa, creados por catedráticos de instituto), centrándose 
principalmente en algunas Comunidades Autónomas españolas. López-Facal (1997) también ha examinado la difusión y diseño de los libros de texto con mayor cuota de mercado, así como la trayectoria académica y experiencia educativa de sus autores.

Una de las aportaciones más relevantes en este campo ha sido el estudio de Segura (2001), el cual estudiaba la proporción de contenidos regionales de Historia en manuales de diferentes Comunidades Autónomas. Como paso previo a dicho análisis se examinaban, en un gran número de centros, las editoriales con mayor presencia en las aulas y se aportaban datos empíricos sobre la aceptación de manuales de distintas regiones. En otros países una parte de estos estudios son innecesarios ya que, por diferentes motivos, se hace pública de forma periódica la información sobre los ejemplares utilizados en las aulas. Esto no sucede en el caso español. El Ministerio de Educación y las asociaciones de editores únicamente muestran algunos datos insuficientemente detallados sobre la facturación global de gran parte del sector y sobre los precios medios de cada producto. Es por ello que algunas investigaciones, como la de Burguera (2006), han venido a completar este vacío con un estudio sobre el índice de utilización de los libros y recursos empleados por una muestra amplia de profesores de Historia; mientras que han aparecido otras publicaciones como las de Rüsen (1997), Valls (2007) o Prats (2012) que ofrecen pautas y criterios a los docentes para elegir manual de Historia y Ciencias Sociales.

\section{ESTUDIOS SOBRE EL PAPEL DE LOS MANUALES \\ EN EL DISEÑO Y DESARROLLO DE LA CULTURA ESCOLAR}

Finalmente encontramos el conjunto de investigaciones denominado como estudios centrados en el papel de los manuales en el diseño y desarrollo de la cultura escolar. Estos trabajos se centran en indagar o aproximarse al "uso real" que se hace de los libros en las aulas o a la forma en que los emplean tanto los docentes como los alumnos, entre otros aspectos. Pese a que estos son factores de gran relevancia para conocer el impacto de los manuales, los impedimentos que implica el estudio sistemático y a lo largo del tiempo de una muestra significativa de docentes (y discentes) sobre el modo de utilización de los libros de texto, así como las prioridades investigativas hacia otras líneas anunciadas, han reducido el número de investigaciones en este campo.

La evidente carencia de estudios de este tipo ha sido manifestada por múltiples autores (Miralles et al., 2011; Valls, 2007,2008) ya que es la principal flaqueza de los estudios sobre manualística en Didáctica de las Ciencias Sociales, así como en la manualística general (Ossenbach, 2010). En este sentido, una vía de perfeccionamiento a incorporar en los próximos años es la combinación de fuentes (Mahamud y Badanelli, 2013), tal y como ha realizado Merchán (2002) con su estudio centrado en el uso del manual de Historia y que se sirve de entrevistas a alumnado y profesorado, así como del análisis documental de los cuadernos de los estudiantes, los exámenes y otros materiales. A pesar de contribuciones puntuales como esta que nos aproximan a aquello que acontece en las aulas, no se han llevado a cabo estudios como el de Stodolsky (1991) en EEUU donde se observaban y comparaban 39 clases (20 de Matemáticas y 19 de Ciencias Sociales) de quinto curso de 
enseñanza básica, o trabajos como el de Lambert (1999) en Gran Bretaña sobre el uso del manual en clases de Geografía. En este período tampoco se han producido investigaciones como la de da Costa (1997) en Brasil sobre el uso del manual que hacen los alumnos del Prácticum de Profesor de Historia, o en un contexto mucho más cercano, como la tesis doctoral de Güemes (1994) que realizaba un análisis del uso del manual de Ciencias Sociales por parte de tres profesoras de Educación Primaria en escuelas canarias.

Sin embargo, el estudio más relevante desarrollado en los últimos años en España ha sido sin duda el de N. Martínez. Esta extensa investigación indaga en los recuerdos que tiene el alumnado de las clases de Historia de Bachillerato en la provincia de Murcia (Martínez y Alarcón, 2016) aportando datos empíricos sobre las funciones de los libros de texto en la labor diaria de las escuelas. Entre otras cosas, este trabajo ha puesto de relevancia el hecho de que los manuales de Historia se constituyeran como una de las partes esenciales en la construcción del Código disciplinar, ya que a pesar de que estos recursos sean valorados de forma desigual entre los distintos agentes educativos (docentes, discentes o familias), su presencia siempre está fuertemente ligada a la Historia que se imparte en los centros. De este modo, atendiendo a los recuerdos del alumnado podemos ver cómo el manual tiene un peso especial en comparación con otros elementos, al estar siempre asociado al quehacer educativo y sobre todo a los sucesos de aula.

Por lo que respecta a la utilización del libro de texto digital en la materia de Ciencias Sociales, son escasos los estudios que se ocupan de esta situación. El motivo debe buscarse en la progresiva implantación de este tipo de manual en las aulas, auspiciada por políticas institucionales y de centros escolares concretos. Pese a todo, caben destacar los avances de la mano de Rivero, que ha realizado un análisis en profundidad de las pautas que llevan a los docentes a usar unos recursos digitales frente a otros, unido a la forma de utilización de la tecnología en las aulas de Geografía-Historia (Flores y Rivero, 2014; Rivero y Trepat, 2010).

\section{METODOLOGÍA DE ANÁLISIS DE LA ADECUACIÓN DIDÁCTICA EN LOS MATERIALES CURRICULARES DE CIENCIAS SOCIALES}

Como hemos ido viendo, el estudio de los manuales escolares - sobre todo en soporte en papel y recientemente también en digital - ha sido una de las principales preocupaciones de la investigación educativa (Escolano, 2013), aunque siguen siendo escasos los trabajos que realizan un análisis en profundidad de determinados elementos o componentes de los materiales escolares y cuyas conclusiones ayudarían a su cambio y mejora. A esto se suma la acuciante necesidad en Didáctica de las Ciencias Sociales de ser más rigurosos y sistemáticos con los métodos de investigación, como así han señalado otras revisiones teóricas anteriores (Miralles et al., 2011). A continuación, planteamos, por tanto, propuestas metodológicas que han derivado en resultados interesantes para el análisis de materiales curriculares en Educación Primaria y Secundaria y que tienen que ver con el estudio de la com- 
plejidad cognitiva demandada a los estudiantes en las diferentes actividades - en papel y digital - e imágenes ofrecidas en estos soportes. Un conocimiento mayor de esa demanda ayudará a un cambio transformador de las tareas sugeridas a los discentes y la producción, seguro, de nuevos materiales adaptados a las necesidades reales de la educación en el siglo XXI.

\section{EL ANÁLISIS DE LA COMPLEJIDAD COGNITIVA REQUERIDA EN ACTIVIDADES DEL LIBRO DE TEXTO}

En primer lugar, planteamos una categorización de las actividades contenidas en los libros de texto según la capacidad cognitiva que exigen, es decir, el nivel de conocimiento y de procesamiento de información que suponen para el alumnado. Para ello partimos de los siguientes supuestos teóricos que están en la base de la propuesta metodológica que presentamos. En primer lugar, la taxonomía de objetivos-etapas de aprendizaje de Bloom, en su revisión adaptada por Anderson y Krathwohl (2001). En segundo lugar, la jerarquización de preguntas de comprensión textual para generar conocimiento declarativo derivada de estudios sobre uso y creación de textos en el aprendizaje de ciencias (Sanjosé et al., 2010) diferenciando entre preguntas literales y de base de texto y preguntas inferenciales, de modelo de situación. Finalmente, la gradación cognitiva de conocimientos procedimentales, de las simples técnicas y destrezas a las estrategias (Pozo, 2008). Así, trazamos tres niveles de complejidad cognitiva en las actividades presentes en los manuales y formulamos el siguiente modelo conceptual de análisis.

Inicialmente, siguiendo esta categorización consideramos como actividades de tipo 1, de complejidad cognitiva baja, aquellas que implican la localización y repetición de información presente en recursos del propio libro: textos académicos, fuentes escritas primarias o secundarias, gráficos, mapas, ejes cronológicos o imágenes. Son las que activan conocimientos declarativos de formulación literal o de base de texto o conocimientos procedimentales como meras destrezas o técnicas. Seguidamente, suponen actividades de tipo 2, de complejidad media, aquellas que requieren comprender la información inserta en el recurso resumiéndola, parafraseándola o esquematizándola; también inicialmente demandan contenidos procedimentales de técnicas, como los establecidos en el tipo anterior. Finalmente se establecen como actividades de tipo 3, de complejidad cognitiva alta, las que suponen analizar, aplicar o evaluar información extraída de diferentes recursos o las que implican la creación de nueva información. Parten del nivel anterior y derivan de la resolución de preguntas inferenciales y de la aplicación de contenidos procedimentales como estrategias. Como ejemplos habría que considerar los ejercicios de empatía, simulaciones o estudios de caso; la redacción aplicando contenidos declarativos aprendidos; la valoración crítica o heurística de información proporcionada por las fuentes; la contrastación de un mismo fenómeno en dos fuentes o de diferentes interpretaciones sobre un mismo hecho; la resolución de preguntas abiertas o problemas de aprendizaje; y finalmente la confección de informes, autoexplicaciones o conclusiones obtenidas fruto del análisis de diferentes recursos (Tabla 1). 


\section{EL ANÁLISIS DE LA DEMANDA COGNITIVA EN LA UTILIZACIÓN DE LAS IMÁGENES}

Como hemos comprobado en el apartado anterior, las imágenes incluidas en los libros de texto han sido examinadas desde diferentes perspectivas en los materiales de Ciencias Sociales en España. En cierta medida esta creciente preocupación por el valor comunicativo y la función didáctica de las representaciones icónicas se puede explicar por la riqueza expresiva de las imágenes, por sus características llamativas o por su relevancia en las sociedades actuales, aunque también por el modo en que gran parte de la psicología educativa de la segunda mitad del siglo XX ha promovido su uso en las situaciones de aprendizaje. Todo esto pone de relieve que la alfabetización visual de niñas y niños sea una parte fundamental de su formación ciudadana, un proceso de aprendizaje en que los docentes deben ayudar a que el alumnado desarrolle criterios de análisis de la información icónica y capacidades críticas y reflexivas sobre estos mensajes. Por todos estos motivos planteamos una categorización similar a la ya planteada sobre las actividades de manuales, pero esta vez centrada exclusivamente en las tareas basadas en imágenes figurativas (imágenes que representan la realidad con un alto grado de similitud, como fotografías, obras pictóricas, etc.).

La propuesta que sugerimos de categorización también se fundamenta en la taxonomía de objetivos-etapas de aprendizaje de Bloom, más concretamente en su revisión adaptada por Anderson y Krathwohl (2001), así como en el resto de supuestos teóricos ya enunciados. El factor diferencial en este caso radica en la naturaleza singular de los mensajes visuales y en el modo en que las personas los interpretan. En este sentido, la categorización de actividades se basa también en la Cognitive Theory of Multimedia Learning, elaborada por Mayer $(2001,2005)$, ya que la mayoría

Tabla 1 - Tipología de demanda cognitiva de las actividades.

\begin{tabular}{ccc}
\hline Tipología & Destrezas demandadas & Ejemplos de aplicación \\
\hline Tipo 1 & $\begin{array}{c}\text { Lectura, descripción, localización, repetición, } \\
\text { reproducción y/o memorización de } \\
\text { información textual o icónica. }\end{array}$ & $\begin{array}{c}\text { Responder preguntas cuya respuesta se } \\
\text { extrae de forma literal en el libro de texto. }\end{array}$ \\
\hline Tipo 2 & $\begin{array}{c}\text { Localizar la idea principal del recurso, } \\
\text { resumir, relacionar, establecer semejanzas } \\
\text { o diferencias entre distintos materiales y, } \\
\text { finalmente, confeccionar sencillos recursos. }\end{array}$ & $\begin{array}{c}\text { Buscar en una fuente externa una } \\
\text { definición y parafrasearla. }\end{array}$ \\
& $\begin{array}{c}\text { Elaborar un gráfico a partir de datos, un } \\
\text { indice cronológico o una tabla. }\end{array}$ \\
\hline Tipo 3 & $\begin{array}{c}\text { Elaborar un video documental sobre } \\
\text { un temalizar, aplicar, evaluar información } \\
\text { fuentes y/o recursos. }\end{array}$ \\
implican la creación de nueva información. & $\begin{array}{c}\text { Crear una historia y/o resolución } \\
\text { de un problema social a partir de } \\
\text { elementos aprendidos. }\end{array}$ \\
\hline
\end{tabular}

Fuente: elaboración propia a partir de Sáiz y Colomer (2014). 
de imágenes presentadas en los libros están asociadas a un texto y esta teoría establece los pasos a seguir para desarrollar aprendizajes y construir representaciones mentales combinando informaciones textuales e icónicas. Las fases de este proceso parten de la selección de términos verbales e icónicos transmitidos por ambos mensajes para derivar en la integración de esa información en el conocimiento previo del sujeto. Asimismo, en nuestro instrumento también se aplican los planteamientos de Sáiz (2015) sobre el aprovechamiento didáctico de las fuentes históricas.

La combinación de todos estos elementos da lugar a la categorización de actividades basadas en imágenes figurativas, así como a los tres niveles de complejidad cognitiva, que se muestran en la Tabla 2.

\section{EL ANÁLISIS COGNITIVO DE LAS ACTIVIDADES CON SOPORTES DIGITALES}

$\mathrm{El}$ aumento de libros de texto en soporte digital, pese a que no son mayoría en los centros escolares actuales, requiere de una metodología nueva que permita comprender las estrategias cognitivas demandadas en los nuevos recursos. Aquí cabe distinguir entre los soportes elaborados por las editoriales - muchas veces limitados a la proyección del libro de texto en papel en otro dispositivo - y los elaborados por el docente siguiendo plataformas predefinidas o de creación de contenidos. La metodología de análisis que planteamos para todos estos recursos parte inicialmente del modelo de Churches (2009) que a su vez está adaptado a partir de la taxonomía de Anderson y Krathwohl (2001) mencionada anteriormente, aunque debemos señalar que esta propuesta metodológica no cuenta aún con suficientes trabajos empíricos. Esta gradación no se encamina a un análisis de las herramientas basadas en TIC, pues estas constituyen los medios, sino que se enfoca en el uso de todas ellas para las estrategias de recordar, comprender, aplicar, analizar, evaluar y crear (Tabla 3).

Tabla 2 - Tipología de demanda cognitiva de las actividades basadas en imágenes.

\begin{tabular}{|c|c|c|}
\hline Tipología & Destrezas demandadas & Ejemplos \\
\hline Tipo 1 & $\begin{array}{l}\text { Observación, descripción, localización, } \\
\text { reproducción, identificación de elementos o } \\
\text { aspectos superficiales y copia de información } \\
\text { textual o icónica. }\end{array}$ & $\begin{array}{l}\text { Responder preguntas cuya respuesta se } \\
\text { extrae de forma literal de la imagen o se } \\
\text { copia del texto que la acompaña. }\end{array}$ \\
\hline Tipo 2 & $\begin{array}{l}\text { Localización de la idea principal, } \\
\text { comparación de elementos y características, } \\
\text { relación, reconocimiento de semejanzas } \\
\text { y/o diferencias entre distintas escenas y } \\
\text { comprensión de la utilidad de la fuente o de } \\
\text { los elementos que aparecen en ella. }\end{array}$ & $\begin{array}{l}\text { Comparar dos fuentes históricas y la } \\
\text { información superficial que aportan. } \\
\text { Buscar información referida a la } \\
\text { imagen o definir algún elemento } \\
\text { incluido en la misma. }\end{array}$ \\
\hline Tipo 3 & $\begin{array}{l}\text { Análisis, aplicación o evaluación de la } \\
\text { información extraída de la imagen y creación } \\
\text { de nueva información considerando sus } \\
\text { características como fuente histórica. }\end{array}$ & $\begin{array}{l}\text { Redactar una historia por medio de } \\
\text { la empatía histórica a partir de la } \\
\text { información obtenida. } \\
\text { Analizar la información de una } \\
\text { imagen argumentando los posibles } \\
\text { sesgos de autoría. }\end{array}$ \\
\hline
\end{tabular}

Fuente: elaboración propia a partir de Bel (2017). 
Tabla 3 - Taxonomía de análisis de la complejidad cognitiva de las actividades que apelan y/o utilizan recursos tecnológicos.

\begin{tabular}{|c|c|}
\hline Términos taxonómicos & Destrezas demandadas en de la época digital \\
\hline Crear & Programar, filmar, animar, bloguear, participar en una wiki, "podcasting". \\
\hline Evaluar & $\begin{array}{c}\text { Comentar en un blog o foro, moderar, colaborar de forma activa en } \\
\text { redes, reelaborar, probar una APP. }\end{array}$ \\
\hline Analizar & Analizar un recurso electrónico, recopilar información de medios. \\
\hline Aplicar & $\begin{array}{l}\text { Jugar, subir archivos a un servidor, compartir, editar información de } \\
\text { una presentación. }\end{array}$ \\
\hline Comprender & Hacer búsquedas avanzadas, categorizar, etiquetar, suscribir. \\
\hline Recordar & Marcar favoritos, buscar, memorizar un contenido cerrado de Internet. \\
\hline
\end{tabular}

Como vemos, cada término clave se asocia a una acción fácilmente comparable con lo exigido en las actividades vinculadas a recursos digitales. Así, vemos tareas que demandan al alumnado buscar información en la red sin mayor pretensión que la copia del contenido literal en otro soporte, lo que lleva a estrategias que requieren un bajo nivel cognitivo y desaprovechan todos los beneficios que la tecnología puede aportar. Por otro lado, existen actividades que requieren de la combinación de varias herramientas digitales y que llevan a procesos creativos donde intervienen estrategias cognitivas complejas: como la elaboración de presentaciones on-line, de creación de contenido de forma colaborativa o la elaboración de video-documentales sobre temática social o histórica (Colomer y Navarro, 2015).

Igualmente, como sucede con el libro de texto en papel, la actividad sugerida está necesariamente mediada por la acción docente: su utilización, cómo la programa, qué momento de la sesión dedica para su desarrollo, cómo la evalúa... por lo que cualquier intento de análisis de la composición de la actividad debería ir unido a la utilización que de la misma hacen los docentes en su contexto escolar.

\section{CONCLUSIONES}

Hace más de 20 años, Jörn Rüsen (1997) sugería que, en una escuela actual y transformadora, si realmente se pretende cambiar la metodología, apostar por la innovación docente y repensar las prácticas de enseñanza en los diferentes contextos, urgían materiales complejos y relevantes que ayudasen al profesorado a interrogarse sobre los problemas de la enseñanza y le permitieran experimentar de un modo autónomo y responsable sus propias estrategias de acción.

Así, este material curricular - el manual escolar — como producto cultural y educativo en transformación constante ocupa un punto central de la investigación, no solo en manualística, sino también en Didáctica de las Ciencias Sociales, la Geografía y la Historia. Esto ha llevado a la generación de líneas de trabajo com- 
plementarias circunscritas a aspectos como las políticas editoriales y de mercado, el análisis de contenidos o su utilización dentro de las aulas. El análisis ha permitido destacar la pluralidad de trabajos centrados en los contenidos y el progresivo desarrollo de investigaciones sobre su adecuación didáctica, así como la escasez de estudios sobre el mercado y los inexistentes sobre el uso real del libro, algo que debería ser compensando en los próximos años en este campo educativo concreto y en la manualística en general (Mahamud y Badanelli, 2013,2016; Ossenbach,2010). La introducción gradual de libros digitales en las aulas en la última década no se ha visto acompañada de suficientes estudios analíticos sobre el contenido, difusión o modos de aprendizaje promovidos por estos, si bien han aparecido numerosas reflexiones sobre su impacto. Pese a que estas preocupaciones son necesarias y aportan interesantes puntos de vista, consideramos que son insuficientes para incidir en la transformación del material escolar.

Es por ello que sugerimos un avance de las investigaciones asociadas al libro de texto de esta materia tomando en cuenta los recursos plurales que se incluyen, ya que esto también ayudaría a superar - en la línea de estudios similares - los métodos de investigación rudimentarios que han caracterizado a la Didáctica de las Ciencias Sociales (Miralles et al., 2011) en el contexto español. El avance en el campo de investigación de los manuales podría partir de un conveniente análisis didáctico de los elementos contenidos en los mismos, como las imágenes o las actividades, algo que, junto a un necesario estudio del texto académico del manual y el examen de recursos complementarios (Mahamud, 2014), puede aportar convenientes conclusiones a la comunidad científica. La propuesta metodológica aquí presentada, por tanto, surge con la modesta pretensión de aunar criterios y evitar la dispersión - y poca claridad en muchas ocasiones - que complica los estudios desarrollados por distintos investigadores o grupos de trabajo de diferentes territorios e instituciones.

\section{REFERENCIAS}

Anderson, L.; Krathwohl, D. A. Taxonomy for learning, teaching and assessing: a revision of bloom's taxonomy of educational objectives. New York: Longman, 2001.

Asociación de Geógrafos Españoles. La geografía en los libros de texto de enseñanza secundaria, 2000. Disponible en: <http://age.ieg.csic.es/docs/00-12-librostext.PDF >. Acceso en: 28 dic. 2017.

Atienza, E.; van Dijк, T. A. Identidad social e ideología en libros de texto españoles de Ciencias Sociales. Revista de Educación, Madrid, n. 353, p. 67-106, sept.-dic. 2010. Disponible en: 〈http://www.revistaeducacion.educacion.es/re353/re353_03.pdf〉. Acceso en: 28 dic. 2017.

Badanelli, A.; Mahamud, K.; Milito, C.; Ossenbach, G.; Somoza, M. Studying history on line, section: school textbooks. Lifelong Learning programme Erasmus. Bruselas: European Commission, 2009. Disponible en: <https:// www.academia.edu/9171913/Studying_History_On_Line._Section_School_ Textbooks?auto=download $>$. Acceso en: 28 dic. 2017. 
BeL,J. C. El papel de las mujeres en la Historia según las imágenes de los libros de texto. Comparación de manuales editados durante la LOE y la LOMCE. AULA: Revista de Pedagogía de la Universidad de Salamanca, Salamanca, n. 22, p. 219-234, 2016.

. Imagen y libros de texto de Historia en Educación Primaria: estudio comparativo a partir de un análisis cualitativo. Revista de Educación, Madrid, n. 377, p. 82-112, 2017. Disponible en: <http://www.mecd.gob.es/revista-de-educacion/numerosrevista-educacion/numeros-anteriores/2017/377/377_4.html>. Acceso en: 28 dic. 2017. Benedito, M.T.; Cervellera, A.; Souto, X. M. Los manuales escolares y la didáctica de la geografía entre 1950 y 1990. In:TianA, A.(Ed.). El libro escolar, reflejo de intenciones políticas e influencias pedagógicas. Madrid: Universidad Nacional de Educación a Distancia, 2012. p. 63-86.

Benso, M.; Rivas, S. La geografía en el libro de texto en la enseñanza secundaria. Uso y producción de manuales en el bachillerato gallego decimonónico. Historia de la Educación, Salamanca, n. 21, p. 153-175, 2002.

Blanco, N. El sexismo en los materiales educativos de la ESO. Sevilla: Instituto Andaluz de la Mujer, 2000.

Boyd, C. P. Historia Patria. Política, historia e identidad nacional en España. 1875-1975. Barcelona: Ediciones Pomares-Corredor, 2000.

Bufrem, L. S.; Sсhmidt, M. A.; Braga, T. M. F. Os manuais destinados a professores como fontes para a história das formas de ensinar. Revista HISTEDBR on-line, Campinas, n. 22, p.120-130, jun. 2006. Disponible en: <http://www.histedbr.fe.unicamp. br/revista/edicoes/22/art09_22.pdf>. Acceso en: 28 dic. 2017.

Burguera, J. Usos y abusos del llibre de text. Perspectiva escolar, Barcelona, n. 302, p. 75-79, feb. 2006.

Buzo, I. La cotidianidad en uso de las TIC en las Ciencias Sociales. La web de recursos de Ciencias Sociales. In: Hernández, J.; Pennesi, F.; Sobrino, D.; Vázquez, A. (Coords.). Experiencias educativas en las aulas del siglo XXI: innovación con TIC. Barcelona: Ariel, 2011. p. 347-350.

Campos, L. Los relatos de la nación. Iconografía de la idea de España en los manuales escolares (1931-1983). Madrid: CEPC, 2010.

CAPEl, H. La estructura física de la tierra según los textos de geografía. In: Araya, M.; Brunet, M.; Melcón, J.; Nadal, F.; Urteaga, L.; Sánchez, I. (Coord.). Ciencia para la burguesía. Barcelona: Publicaciones de la Universitat de Barcelona, 1983. p. 171-208.

;: SolÉ, J.; URteaga, L. El libro de geografía en España, 1800-1939. Madrid: Universitat, 1988.

Castillejo, E. Legitimación del sistema capitalista a través de la enseñanza de la historia durante el franquismo. Huarte de San Juan. Geografía e Historia, Pamplona, n. 10, p. 191-256, 2003.

. Mito, legitimación y violencia simbólica en los manuales escolares de Historia del franquismo. Madrid: UNED, 2008.

Churches, A.Taxonomía de Bloom para la Era Digital.Eduteka, p. 1-12,2009. Disponible en: <http://www.eduteka.org/articulos/TaxonomiaBloomDigital >. Acceso en: 28 dic. 2017. 
Císcar, J.; Santiago, J.; Souto, X. M. Identidades nacionales y territorialidad en los libros de texto. Los estereotipos enciclopédicos en la geografía escolar. Scripta Nova: revista electrónica de geografía y ciencias sociales, Barcelona, v. 16, n. 418, 2012. Disponible en: <http://www.ub.edu/geocrit/sn/sn-418/sn-418-36.htm>. Acceso en: 28 dic. 2017. Colomer, J. C.; Navarro, Y. A produção de documentários como recurso didático tic para o ensino de geografia e história: metodologia e proposta de trabalho. Giramundo: Revista de Geografia do Colégio Pedro II, Rio de Janeiro, v. 2, n. 3, p. 31-38, 2015. Disponible en: <http://www.cp2.g12.br/ojs/index.php/GIRAMUNDO/article/ view/205/202>. Acceso en: 28 dic. 2017.

Cuesta, R. Sociogénesis de una disciplina escolar: la historia. Barcelona: Ediciones Pomares-Corredor, 1997.

Da Costa, A.M. S. Práctica pedagógica e tempo escolar: o uso do livro didático no ensino da Histórica. São Paulo: Pontificia Universidade Católica De São Paulo, 1997.

Del Castillo, A. S.. ¡La Enseñanza de la Historia sin mujeres! Género, currículum escolar y libros de texto: una relación problemática. Didáctica de las Ciencias Experimentales y Sociales, València, n. 29, p. 43-59, 2015.

Escolano, A. La segunda generación de manuales escolares. In: .(Ed.). Historia ilustrada de libro escolar en España: de la posguerra a la reforma educativa. Madrid: Fundación Germán Sánchez Ruipérez, 1998. p. 19-48.

. La recepción de los modelos de la Escuela Nueva en la manualística de comienzos del siglo XX. Historia de la educación: Revista Interuniversitaria, Salamanca, n. 25, p. 317-340, 2006.

. La manualística en España: dos décadas de investigación (1992-2011). In: Meda, J.; Badanelli, A. (Ed.). La historia de la cultura escolar en Italia y en España: balances y perspectivas. Macerata: Edizione Universitá di Macerata, 2013.p. 17-46.

Fernández, A. La importancia de ser llamado «libro de texto». Hegemonía y control del currículo en el aula. Buenos Aires: Miño y Dávila Editores, 2005.

Flores, H. C.; Rivero, P. ¿Cómo selecciona el profesorado recursos digitales para enseñar la Historia? Clio: History and History Teaching, Zaragoza, n. 40, p. 1-7, 2014. Disponible en: <http://clio.rediris.es/n40/articulos/FloresRivero2014.pdf>. Acceso en: 28 dic. 2017.

García-Puchol, J. Los textos escolares de historia en la enseñanza española, 1808-1900: análisis de su estructura y contenido. Barcelona: Edicions Universitat Barcelona, 1993.

Gómez, C. J. Pensamiento histórico y contenidos disciplinares en los libros de texto. Un análisis exploratorio de la Edad Moderna en $2^{\circ}$ de la ESO. Ensayos. Revista de la Facultad de Educación de Albacete, Albacete, v. 29, n. 1, p. 131-158, 2014. Disponible en: <https://www.revista.uclm.es/index.php/ensayos/article/view/498/454>. Acceso en: 28 dic. 2017.

.; López, A. Las imágenes de los libros de texto y su función en la enseñanza de la historia. Diseño de un instrumento de análisis. Enseñanza de las Ciencias Sociales, Barcelona, n. 13, p. 17-29, 2014. Disponible en: <http://www.raco.cat/index.php/ EnsenanzaCS/article/viewFile/285716/37368>. Acceso en: 28 dic. 2017. 
.; Molina, S.; Pagán, B. Los manuales de Ciencias Sociales y la enseñanza de la Historia del Arte en 2o de ESO. Ensayos: Revista de la Facultad de Educación de Albacete, Albacete, v. 27, n. 1, p. 69-88, 2012. Disponible en: <https://dialnet.unirioja. es/descarga/articulo/4202766.pdf >. Acceso en: 28 dic. 2017.

Gómez-Mendoza, M. A.; Braga, T. M. F.; Rodríguez-Rodríguez, J. (Comp.). Balance y análisis de la investigación sobre el libro de texto escolar y los medios digitales. Pereira: Universidad Tecnológica de Pereira, 2016.

Güemes, R. M. Libros de texto y desarrollo del currículo en el aula. Un estudio de casos. Tenerife: Universidad de La Laguna, 1994.

LAmbert, D. Exploring the use of textbooks in the Key Stage 3 geography classrooms: a samall-case study. The Curriculum Journal, Londres, v. 10, n. 1, p. 85-105, 1999.

López-Facal, R. Libros de texto: sin novedad. Con-Ciencia Social, Salamanca, n. 1, p. 51-76, 1997.

. Nacionalismos y europeísmos en los libros de texto: identificación e identidad nacional. Clio E Asociados, Buenos Aires, n.14, p. 3-9, 2010.

Mahamud, K. Context, texs and representativeness. A methodological approach to school textbooks research.In: Knecht, P.; Matthes, E.; Schütze, S.; Аамотsbakken, B. (Coord.). Methologoie und Methoden der Schulbuch-und Lebrmittelforschung. Kempten: Klinkhardt, 2014. p. 31-49.

.; Badanelli, A. M. El cuaderno escolar como objeto de estudio: una aproximación a los avances metodológicos en manualística. In: MedA, J.; BadANelli, A. (Ed.). La historia de la cultura escolar en Italia y en España: balances y perspectivas. Macerata: Edizione Universitá di Macerata, 2013. p. 201-228.

.;_____. Los contextos de transmisión y recepción de los manuales escolares: Una vía de perfeccionamiento metodológico en manualística. História da Educação, Porto Alegre, v. 20, n. 50, p. 29-48, sept.-dic. 2016. Disponible en: <http://seer.ufrgs. br/index.php/asphe/article/view/62455>. Acceso en: 28 dic. 2017.

Martín, I. La webquest en el área de ciencias sociales: aprendizaje de las TIC en contextos educativos. Íber: Didáctica de las ciencias sociales, geografía e historia, Barcelona, n. 41, p. 77-96, jul.-sept. 2004.

Martínez-Bonafé, J. Los libros de texto como práctica discursiva. Revista de la asociación de sociología de la educación (RASE), Madrid, v. 1, n. 1, p. 62-73, 2008.

Martínez, N.; Alarcón, M. D. La utilización del libro de texto de Historia de España dentro y fuera del aula: alumnos, manuales, huella, interpretación y contexto. Murcia: Universidad de Murcia, 2016.

Mayer, R. E. Multimedia learning. Psychology of Learning and Motivation, Illinois, n. 41, p. 85-139, 2001.

. (Ed.). The Cambridge handbook of multimedia learning. Cambridge: Cambridge University Press, 2005.

Merchán, F.J. El Estudio de la clase de Historia como campo de producción del currículo. Enseñanza de las Ciencias Sociales, Barcelona, n. 1, p. 41-54, 2002. Disponible en: <http:// www.raco.cat/index.php/EnsenanzaCS/article/view/126126>. Acceso en: 28 dic. 2017. 
Miguel, R. M. Geoinformación e innovación en la enseñanza-aprendizaje de la geografía: un reto pendiente en los libros de texto de secundaria. Didáctica de las Ciencias Experimentales y Sociales, València, n. 27, p. 67-90, 2013.

Miralles, P.; Molina, S.; Ortuño, J. La investigación en Didáctica de las Ciencias Sociales. Educatio siglo XXI, Murcia, v. 29, n. 1, p.149-174, 2011. Disponible en: <http:// revistas.um.es/educatio/article/view/119921/112891>. Acceso en: 28 dic. 2017.

Ossenbach, G. Manuales escolares y patrimonio histórico-educativo. Educatio Siglo XXI, Murcia, v. 28, n. 2, p. 115-132, 2010. Disponible en: <http://revistas.um.es/ educatio/article/view/111991 >. Acceso en: 28 dic. 2017.

Parra, D.; Colomer, J. C.; Sáiz, J. Las finalidades socioeducativas de las Ciencias Sociales en el marco de la LOMCE. Educación infantil y primaria. Íber: Didáctica de las ciencias sociales, geografía e historia, Barcelona. n. 79, p. 8-14, abr.-jun. 2015.

Africanismo e arabismo no relato histórico escolar: Espanha, 1939-1956. História. Revista da FLUP, Porto, IV Série, v. 6, p. 89-101, 2016. Disponible en: <http:// ler.letras.up.pt/uploads/ficheiros/14576.pdf>. Acceso en: 28 dic. 2017.

Peirats, J.; Gallardo, I. M.; San Martín, Á.; Waliño, M.J. Análisis de la industria editorial y protocolo para la selección del libro de texto en formato digital. Profesorado. Revista de curriculum y formación del profesorado, Granada, v. 20, n. 1, p. 75-89, 2016. Disponible en: <https://recyt.fecyt.es//index.php/profesorado/article/view/49869/ pdf_4>. Acceso en: 28 dic. 2017.

Pozo,J. I. Aprendices y maestros: la psicología cognitiva del aprendizaje. Madrid: Alianza Editorial, 2008.

Pozo-Nogales, A. Enseñanza de la historia en la escuela española entre 1931-1970. Análisis legislativo-pedagógico y su implantación obligatoria en los libros de texto. Clío: History and History Teaching, Zaragoza, n. 40, p. 28-41, 2014. Disponible en: <http:// clio.rediris.es/n40/articulos/pozo2014.pdf>. Acceso en: 28 dic. 2017.

Prats, J. (Dir.). Los jóvenes ante el reto europeo: conocimientos y expectativas del alumnado de educación secundaria. Barcelona: Fundación La Caixa, 2001.

. Criterios para la elección del libro de texto de historia. Íber: Didáctica de las ciencias sociales, geografía e historia, Barcelona, n. 70, p. 7-13, ene.-abr. 2012.

Rausell, $H$. Tres veces olvidadas, tres veces excluidas.: La presencia de las mujeres marginadas en los manuales de historia de la ESO. Clio: History and History Teaching, Zaragoza, n. 41, p. 1-22, 2015. Disponible en: <http://clio.rediris.es/n41/articulos/ Rausell2015.pdf >. Acceso en: 28 dic. 2017.

Rivero, P.; Trepat, C. A. Didáctica de la historia y multimedia expositiva. Barcelona: Graó, 2010.

Rodríguez, R.; Simón, M. del M. La construcción de la narrativa nacional española en los manuales escolares de Educación Primaria. Ensayos: Revista de la Facultad de Educación de Albacete, Albacete, v. 29, n. 1, p. 101-113, 2014. Disponible en:<https://www.revista.uclm.es/index.php/ensayos/article/view/502/459>. Acceso en: 28 dic. 2017. 
Rodríguez-Rodríguez, J.; Martínez-Bonafé, J. Libros de texto y control del curriculum en el contexto de la sociedad digital. Cadernos CEDES, Campinas, v. 36, n. 100, p. 319-336, sept.-dic. 2016. Disponible en: <http://www.scielo.br/pdf/ccedes/ v36n100/1678-7110-ccedes-36-100-00319.pdf>. Acceso en: 28 dic. 2017.

Rodríguez-Rodríguez, J.; Martínez-Bonafé, J.; Braga, T. Ni la defensa ingenua ni la denuncia vacía: contribuciones para el análisis de las relaciones entre los libros de texto impreso y digitales. Profesorado, Revista de Curriculum y Formación del Profesorado, Granada, v. 20, n. 1, p. 1-8, 2016. Disponible en: <https://recyt.fecyt.es/index.php/ profesorado/article/view/51007>. Acceso en: 28 dic. 2017.

RüSEN, J. El libro de texto ideal. Reflexiones en torno a los medios para guiar las clases de historia. Íber: Didáctica de las ciencias sociales, geografía e historia, Barcelona, n. 12, p. 79-93, abr.-jun. 1997.

SÁez-Rosenkranz, I. Análisis de las actividades de los libros de texto de Historia, Geografía y Ciencias Sociales de educación básica en Chile. 2016. 446f. Tesis (Doctorado de Didáctica de las Ciencias Sociales y del Patrimonio) — Universitat de Barcelona, Barcelona, 2016. Sárz, J. Actividades de libros de texto de Historia, competencias básicas y destrezas cognitivas, una difícil relación: análisis de manuales de $1^{\circ}$ y $2^{\circ}$ de ESO. Didáctica de las ciencias experimentales y sociales, València, n. 25, p. 37-64, 2011.

.La Península Ibérica medieval y las identidades en los actuales libros de texto de historia de $2^{\circ}$ de ESO. Íber: Didáctica de las ciencias sociales, geografía e historia, Barcelona, n. 70, p. 67-77, ene.-abr. 2012.

. Educación histórica y narrativa nacional. 2015. 440f. Tesis (Doctorado en Didácticas Específicas) - Universitat de València, València.

.; Colomer, J. C. ¿Se enseña pensamiento histórico en los libros de texto de Educación Primaria? Clío. History and History teaching, Zaragoza, v. 40, p. 1-19, 2014. Disponible en: <http://clio.rediris.es/n40/articulos/saizycolomer2014.pdf>. Acceso en: 28 dic. 2017.

SANJosÉ, V.; Fernández,J.-J.; VidAL-Abarca, E. Importance of information processing skills on the comprehension of scientific texts. Infancia y Aprendizaje, Madrid, v. 33, n. 4, p. 529-541, 2010.

Sснмidt, M. A. M. S. História do ensino de história no Brasil: uma proposta de periodização. História da Educação, Porto Alegre, v. 16, n. 37, p. 73-91, mayo/ago. 2012. Disponible en: <http://seer.ufrgs.br/index.php/asphe/article/view/24245>. Acceso en: 28 dic. 2017.

Segura, A. (Coord.). Els llibres d'història, l'ensenyament de la història i altres històries. Barcelona: Fundació Bonfill, 2001.

Stodolsкy, S. La importancia del contenido en la enseñanza. Actividades en las clases de matemáticas y ciencias sociales. Barcelona: Paidós, 1991.

Teıve, G.M.G. Caminhos teórico-metodológicos para a investigação de livros escolares: contribuição do Centro de Investigación MANES. Revista Brasileira de Educação, Rio de Janeiro: ANPEd; Campinas: Autores Asociados, v. 20, n. 63, p. 827-843, oct.-dic. 2015. 
Tiana, A. El libro escolar, reflejo de intenciones políticas e influencias pedagógicas. Madrid: Universidad Nacional de Educación a Distancia, 2000.

VALLs, R. Historiografía escolar española: siglos XIX-XXI. Madrid: UNED, 2007.

La enseñanza de la historia y los textos escolares. Buenos Aires: Libros del Zorzal, 2008.

\section{SOBRE LOS AUTORES}

Juan Carlos Bel Martínez es doctorando en didáctica de la historia por la Universitat de València (España).

E-mail: belmartinezjc@gmail.com

Juan Carlos Colomer Rubio es doctor en Historia por la Universitat de València (España). Profesor de la misma institución.

E-mail: juan.colomer@uv.es

Recibido el 27 de julio de 2017

Aprobado el 31 de enero de 2018 